\title{
BAKTI SOSIAL KANDIDAT SARJANA MENGABDI (KSM) SEBAGAI UPAYA PENANGGULANGAN PENYEBARAN COVID-19
}

\author{
Dwi Fita Heriyawati' ${ }^{*}$, Moch Wasi' Al Fahmi' ${ }^{2}$, Muhammad Prama Cahya Ramadhani², \\ Ainul Yakin², Alex Sakar Ramadhan², Rachmad Tri Fajar Hidayat ${ }^{2}$, Muhammad Dziki \\ Aminulloh'2, Febri Didin Ardianto², Siti Hujjatul Islamiyah'2, Reynaldi Aprilianto', \\ Mifthuddin $^{2}$, Karina Wahyu Ariyanti ${ }^{3}$, Annisa Nurul Imani ${ }^{3}$, Adhelya Ludfy Pratiwi ${ }^{3}$, \\ Ghufrony Darwis ${ }^{2}$ \\ ${ }^{1}$ Fakultas Keguruan dan Ilmu Pendididkan, Universitas Islam Malang \\ ${ }^{2}$ Fakultas Hukum, Universitas Islam Malang \\ ${ }^{3}$ Fakultas Ekonomi dan Bisnis, Universitas Islam Malang \\ *korespondensi email: dwifitaheriyawati@unisma.ac.id
}

\begin{abstract}
ABSTRAK
Pandemi Covid-19 telah menyebabkan keterbatasan interaksi antar masyarakat, selain itu juga menyebabkan tidak dapat dilaksanakannya KSM-T kelompok 86 secara bersama-sama di satu lokasi sehingga terbagi menjadi 3 (tiga) lokasi yaitu, Kabupaten Malang, Kabupaten Sampang, dan Kabupaten Bima. Salah satu permasalahan yang ada dalam masyarakat, adalah kurangnya kepedulian tentang pentingnya menerapkan protokol kesehatan di masa pandemi Covid-19. Terkait hal tersebut mahasiswa KSM-T Kelompok 86 mengangkat program penerapan protokol kesehatan di masa pandmi Covid-19 yaitu:1) Meningkatnya kesadaran masyarakat akan pentingnya menerapkan protokol kesehatan; 2) Membantu Pemerintah Desa dan masyarakat sekitar untuk mencegah penularan Covid-19; 3) Membantu memutus rantai Covid-19 berbasis wilayah. Hasil dari pogram kerja yang telah diterapkan adalah terciptanya kesadaran masyarakat untuk mematuhi protokol kesehatan dalam upaya penanggulangan penyebaran Covid-19 di lokasi tempat tinggal masing-masing peserta KSM serta meningkatnya kesadaran dan pengetahuan tentang bahaya Covid-19 di kalangan masyarakat. Selain itu masyarakat mulai rutin memakai masker, handsanitizer, dan menjaga jarak ketika melakukan interaksi dengan masyarakat lainnya.
\end{abstract}

Kata Kunci: pandemi covid-19; pemerintah desa; protokol kesehatan

\section{PENDAHULUAN}

Penyebaran COVID-19 yang marak sekali menimpa masyarakat dunia dan juga di Indonesia membawa dampak yang sangat membahayakan bagi masyarakat. Dampak yang di rasakan secara langsung, bukan hanya dari segi kesehatan, namun juga dari segi sosial dan ekonomi (Harapan et al., 2020; Safi et al., 2021). Dalam rangka membantu upaya pemerintah dalam penanggulangan penyebaran Covid-19, maka program Kandidat Sarjana Mengabdi (KSM) yang dilaksanakan oleh Universitas Islam Malang di fokuskan pada upaya penanggulangan penyebaran Covid-19. Kegiatan Kandidat sarjana mengabdi dilakukan dengan berbasis domisili. Hal ini dilakukan untuk meminimalisir penyebaran Covid-19. Dalam hal ini mahasiswa sebagai bagian dari masyarakat dapat melakukan kegiatan KSM guna menerapkan keilmuan yang selama ini telah di tempuh di bangku kuliah. Masyarakat yang merupakan sasaran mahasiswa sebagai tempat dan sarana pengabdian yang telah 
dilakukan selama kurang lebih satu bulan, akan memberikan edukasi perlunya penerapan protokol kesehatan secara ketat kepada masyarakat sekitar domisili mahasiswa.

Terdapat 3 tempat pengabdian yaitu Kabupaten Malang, Kabupaten Sampang, dan Kabupaten Bima yang di lakukan oleh mahasiswa. Hal ini dikarenakan jarak yang tidak memungkinkan untuk mahasiswa sebagai anggota kelompok 86 untuk melakukan program kerja secara bersamaan. Ditambah lagi karena keadaan yang tidak memungkinkan akibat pandemi COVID-19 menyebabkan mahasiswa tidak dapat melaksanakan program kerja secara bersama-sama. Sehingga alternatif yang dilakukan adalah mahasiswa melakukan program kerja KSM-T dengan memberikan edukasi kepada warga disekitar domisili masingmasing anggota kelompok 86 untuk mematuhi protokol kesehatan yang telah di sosialisasikan oleh pemerintah. Minimnya kesadaran dan pengetahuan masyarakat mengenai pandemi COVID-19 menjadi salah satu alasan tersusunnya program kerja mahasiswa Kandidat Sarjana mengabdi (KSM) kelompok 86.

Berdasarkan uraian diatas, maka mahasiswa Kandidat Sarjana Mengabdi kelompok 86 KSM-T Unisma berinisiatif membantu masyarakat disekitar domisili mereka dalam hal pencegahan COVID-19 baik secara langsung maupun tidak langsung dan mengajak serta Pemerintah Desa untuk bergabung dalam menjalankan program-program kerja yang telah tersusun dan terencana. Program Mahasiswa Kandidat Sarjana Mengabdi (KSM) dilaksanakan dengan tujuan agar masyarakat sekitar yang pada awalnya masih belum mengetahui bahaya COVID-19 dan masih kurang peduli terhadap keselamatan diri sendiri dan orang lain dapat mulai mengerti dan memahami tentang Bahaya penyebaran Covid-19. Wujud nyata kontribusi mahasiswa kandidat sarjana mengabdi (KSM) yaitu dengan melakukan penyuluhan bagi warga sekitar, sosialisasi kesadaran penerapan protokol kesehatan secara ketat dan bakti sosial. Dengan demikian mahasiswa KSM-T Unisma Kelompok 86 berharap agar edukasi dan penyuluhan serta bakti sosial yang telah dilakukan dapat membantu Pemerintah Desa dan masyarakat sekitar untuk meminimalisir penyebaran COVID-19.

\section{METODE}

Pelaksanaan KSM-T Kelompok 86 dilakukan dengan beberapa metode. Hal ini dikarnakan oleh perbedaan tempat pelaksanaan KSM-T pada kelompok 86. Metode yang dilakukan antara lain:

1. Koordinasi

Pada hari petama dilaksanakannya KSM-T Unisma Kelompok 86, anggota kelompok melakukan koordinasi mengenai Tema untuk menentukan program kerja masingmasing domisili.

2. Perizinan

Mahasiswa KSM-T Kelompok 86 melakukan perizinan kepada pihak Pemerintah Desa di lokasi masing-masing serta memaparkan program kerja yang akan dilaksanakan selama berlangsungnya kegiatan KSM-T.

3. Pendataan

Metode ini dilakukan oleh anggota kelompok yang berlokasi di Desa Pandanlandung Kecamatan Wagir Kabupaten Malang. Kegiatan ini melibatkan 3 mahasiswa KSM-T Unisma, 4 Kepala Dusun yaitu Dusun Santren, Dusun Krajan, Dusun Sigromilir, Dusun Pandan Selatan serta Sekretaris Desa selaku Koordinator Satgas Covid-19 Desa Pandanlandung.

4. Sosialisasi
a. Lokasi Desa Patapan Kec. Torjun Kab. Sampang 
Program kerja yang dilakukan adalah sosialisasi mengenai protokol kesehatan, kegiatan ini melibatkan 1 mahasiswa domisili Desa Patapan serta masyarakat sekitar. Kegiatan sosialisasi ini bertujun untuk meningkatkan kesadaran dan pengetahuan masyarakat tentang Covid-19. Selain tentang pentingnya menerapkan protokol kesehatan juga telah disosialisasikan kepada masyarakat tentang hukum menggunakan senjata tajam. Kegiatan ini bertujun agar masyarakat sadar hukum tentang bahayanya penggunaan senjata tajam secara sembarangan.

b. Lokasi Desa Laju Kec. Langgudu Kab. Bima

Program kerja yang dilakukan adalah sosialisasi dengan cara memberikan edukasi tetang bahaya dan cara pencegahan Covid-19 secara umum. Pelaksanaan program kerja di Desa Laju melibatkan 1 mahasiswa yang berdomisili di Desa Laju Kec. Langgudu Kab. Bima serta masyarakat sekitar.

5. Penyerahan Bantuan Sosial

Metode ini dulakukan di setiap lokasi KSM-T guna menunjang berjalannya program kerja KSM-T setiap mahasiswa di masing-masing lokasi. Bantuan sosial yang dimaksud antara lain:

a. Bantuan Bahan Pokok

Progam kerja penyerahan bantuan bahan pokok dilakukan oleh mahasiswa KSM-T lokasi Desa Pandanlandung. Bantuan ini disalurkan melalui Lumbung pangan Desa dengan sasaran masyarakat yang melakukan isolasi mandiri. Program kerja ini melibatkan mahasiswa KSM-T lokasi Desa Pandanlandung serta melibatkan langsung Pemerintah Desa

b. Pembagian masker dan handsanitizer

Program kerja ini dilaksanakan di 2 lokasi yaitu Desa Laju dan Desa Patapan. Dalam program kerja ini melibatkan 2 mahasiswa dengan domisili yang berbeda serta masyarakat sekitar.

\section{HASIL DAN PEMBAHASAN}

Pelaksanaan KSM-T pada tahun 2021 yang dilakukan berbasis domisili masingmasing anggota kelompok dikarenakan masih belum usainya pandemic Covid-19 yang terjadi diseluruh Indonesia. Mengingat masih belum usainya pandemi Covid-19, maka tidak memungkinkan bagi mahasiswa untuk melakukan program kerja kandidat sarjana mengabdi pada satu lokasi secara bersamaan. Dengan satu tema yang sama yaitu "Peran Serta Mahasiswa dalam Menanggulangi Covid-19 di kalangan Pemerintah Desa dan Masyarakat Desa masing-masing."

Pandemi Covid-19 yang membahayakan, hasil pengamatan mahasiswa peserta kandidat sarjana mengabdi terhadap masyarakat yaitu masyarakat masih banyak yang mengabaikan adanya Covid-19 dan mengabaikan penerapan protocol kesehatan yang telah dicanangkan oleh pemerintah. Hal ini bisa dilihat dengan masih banyaknya masyarakat yang pergi beinteraksi tanpa menggunakn masker, tidak mencuci tangan, dan tidak menjaga jarak.

Berdasarkan kondisi yang seperti itu mahasiswa KSM-T berinisiatif membantu Pemerintah Desa serta mengajak satgas Covid-19 untuk ikut serta berpartisipasi dalam mendukung dan melaksanakan penyuluhan penerapan 3M (mencuci tangan, menggunakan masker dan menjaga jarak) dan memantau pelaksanaan protokol kesehatan 3M secara ketat. Selain itu untuk mendukung program 3M dalam rangka menghambat penyebaran Covid-19, maka mahasiswa KSM-T Kelompok 86 juga melakukan bakti sosial dengan memberikan bantuan kepada masyarakat yang terdampak pandemic Covid-19 di daerah masing-masing. 


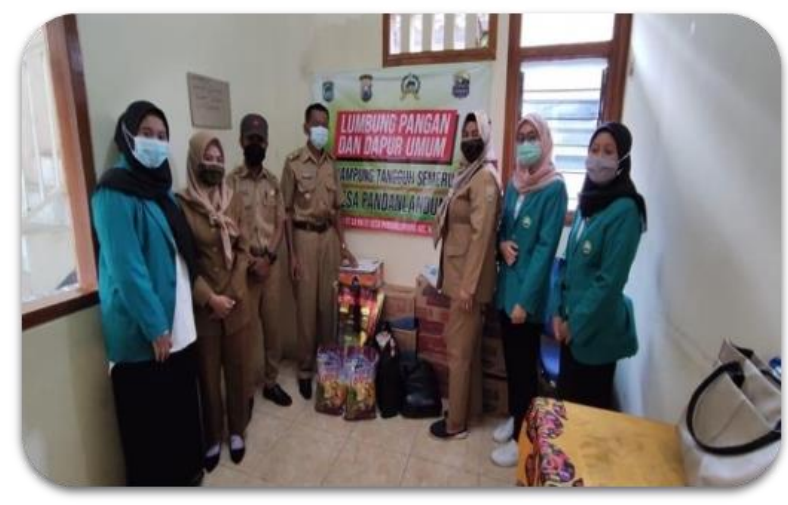

Gambar 1. Pelaksanaan bakti sosial

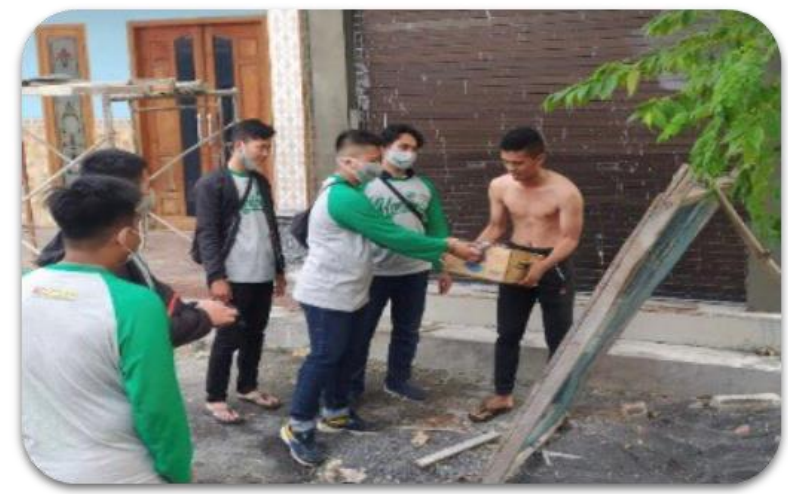

Gambar 2. Penyerahan bantuan pada warga terdampak Covid-19

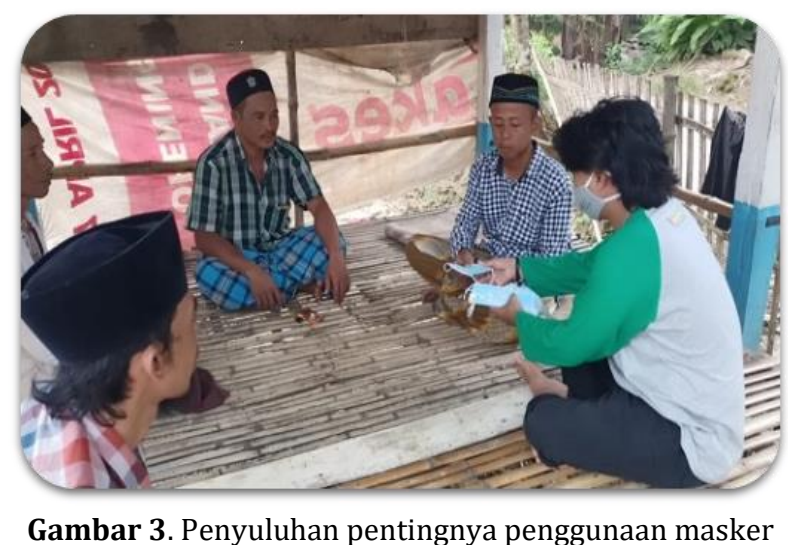

Pelaksanan program penyuluhan dan bakti sosial ini bertujuan agar Pemerintah Desa khususnya masyarakat di Desa Pandanlandung, Desa Laju, Desa Patapan dan Desa Tumunggung memberikan contoh secara langsung dan memberikan edukasi kepada masyarakat desa agar dapat menerapkan protokol kesehatan pada saat menjalankan aktivitas bermasyarakat secara benar dan dengan kesadaran diri (Ulumiyah et al., 2013; Suwardianto, 2015). Selain itu dalam rangka mencegah penyebaran Covid-19 meminimalisir kasus konfirmasi Covid-19 yang terdapat di masyaraat sekitar, sehingga terciptanya lingkungan sehat dan masyarakat yang sadar akan pentingnya menerapkan protokol kesehatan khususnya di masa pandemi Covid-19 ini dapat terwujud dengan baik.

Kegiatan penyuluhan, sosialisasi dan bakti sosial yang dilakukan oleh Mahasiswa KSM-T Unisma Kelompok 86 dalam pelaksanaanya di lapangan juga didampingi dan selalu di support oleh Pemerintah Desa. Sehingga kegiatan pelaksanaan penyuluhan penerapan protokol kesehatan 3M dan bakti sosial sebagai Program kerja mahasiswa Kandidat Sarjana 
Mengabdi (KSM) yang di laksanakan telah sejalan dan berkesinambungan dengan program dan tujuan Pemerintah Desa dalam hal pencegahan penularan Covid-19

\section{KESIMPULAN}

Berdasarkan pembahasan kegiatan KSM-T kelompok 86, dapat disimpulkan bahwa program kerja KSM-T kelompok 86 dalam memberdayakan masyarakat Desa terhadap pentingnya menerapkan protokol kesehatan di masa pandemi Covid-19 ini dapat terlaksana dengan baik. Pemerintah Desa dan masyarakat menerima serta mendukung untuk berartisipasi dalam merampungkan kegiatan penyuluhan, sosialisasi 3M, dan bakti sosial yang dilaksanakan oleh mahasiswa peserta Kandidat Sarjana Mengabdi (KSM) dengan baik. Masyrakat mulai meningkat pemahamannya terhadap bahaya Covid-19. Masyarakat juga mulai menyadari pentingnya menenerapkan protokol kesehatan 3M dalam kegiatan keseharian mereka. Meningkatnya kesadaran masyarakat tentang penerapan protocol kesehatan 3M ini diharapkan mampu membantu menanggulangi penyebaran Covid-19 di Indonesia.

\section{UCAPAN TERIMA KASIH}

Ucapan terima kasih kami sampaikan kepada UNISMA dan juga Pemerintah Daerah Desa Wagir, Kabupaten Malang, Pemerintah Kabupaten Sampang, dan Kabupaten Bima yang telah mendukung terlaksananya kegiatan Kandidat Sarjana Mengabdi (KSM) kelompok 86. Teriring doa semoga Allah SWT selalu melindungi dan merahmati kita semua.

\section{DAFTAR RUJUKAN}

Harapan, H., Itoh, N., Yufika, A., Winardi, W., Keam, S., Te, H., Megawati, D., Hayati, Z., Wagner, A. L., \& Mudatsir, M. (2020). Coronavirus disease 2019 (COVID-19): A literature review. Journal of Infection and Public Health, 13(5), 667-673. https://doi.org/https://doi.org/10.1016/j.jiph.2020.03.019

Safi, I., Candra, A. I., Widodo, S. R., Santoso, A., Heryanto, B., Winarti, E., \& Rahmadi, A. N. (2021). Pembuatan masker dan bilik disinfektan sebagai upaya membantu masyarakat terdampak covid-19. Jurnal Inovasi Hasil Pengabdian Masyarakat (JIPEMAS), 4(1), 36-45. https://doi.org/10.33474/jipemas.v4i1.7524

Suwardianto, S. (2015). Peranan Kepala Desa Dalam Pemberdayaan Masyarakat di Desa Sidoagung Kecamatan Godean Kabupaten Sleman. Universitas Negeri Yogyakarta.

Ulumiyah, I., Gani, A. J. A., \& Mindarti, L. I. (2013). Peran Pemerintah Desa Dalam Memberdayakan Masyarakat Desa (Studi Pada Desa Sumberpasir Kecamatan Pakis Kabupaten Malang). Jurnal Administrasi Publik Mahasiswa Universitas Brawijaya, 1(5),

890-899. http://administrasipublik.studentjournal.ub.ac.id/index.php/jap/article/view/148 